Témoigner Témoigner. Entre histoire et mémoire

Getuigen Revue pluridisciplinaire de la Fondation Auschwitz

$123 \mid 2016$

Traduire le témoignage

\title{
The Belgian Asylum Interview: The Implications of Lingua Franca English Usage
}

L'usage de l'anglais comme lingua franca : implications pour l'entretien d'asile en Belgique

\section{Katrijn Maryns}

\section{(2) OpenEdition}

\section{Journals}

Electronic version

URL: https://journals.openedition.org/temoigner/5265

DOI: $10.4000 /$ temoigner.5265

ISSN: 2506-6390

Publisher:

Éditions du Centre d'études et de documentation Mémoire d'Auschwitz, Éditions Kimé

Printed version

Date of publication: 1 October 2016

Number of pages: 113-126

ISBN: 987 2-9600926-4-6

ISSN: 2031-4183

Electronic reference

Katrijn Maryns, "The Belgian Asylum Interview: The Implications of Lingua Franca English Usage",

Témoigner. Entre histoire et mémoire [Online], 123 | 2016, Online since 02 November 2021, connection on 04 November 2021. URL: http://journals.openedition.org/temoigner/5265 ; DOI: https://doi.org/ 10.4000/temoigner.5265 


\section{The Belgian Asylum Interview The Implications of Lingua Franca English Usage}

$\rightarrow$ Katrijn Maryns

Ghent University

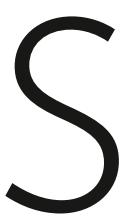

everal studies in applied linguistics have found that the way linguistic diversity tends to be underestimated in institutional practice conflicts with contemporary poststructuralist ideas about language prevailing in the academic field (Pavlenko \& Blackledge 2004; Rampton 2006; Blommaert 2010). Even English, despite its unparalleled global character, tends to be institutionally deployed as a uniform standard language, regardless of who the interlocutors are or what contexts it is used in (Silverstein 1996; Milroy 2001; Canagarajah 2013). Research on the use of English in immigration encounters has demonstrated how dominant standard language and "English-only" ideologies systematically disadvantage participants having disparate access to the institutional language (Gumperz 1982; Haviland 2003; Maryns 2005, 2006; Eades 2008; Guido 2008; Roberts 2012; Angermeyer 2013). To date, the research focus has been primarily on the complexities of "incoming" immigrant Englishes as problematic resources in the interaction with Anglosphere host institutions. In contrast, the interactional dynamics of immigration encounters in which none of the participants use English as a first language (L1), as is generally the case in mainland European host institutions, have been relatively unexplored.

This article aims to map out the scope and context of such an immigration encounter in which English is used as a lingua franca, viz. the Belgian asylum procedure. Drawing on analysis of first hand ethnographic data on language and interaction in the Belgian asylum procedure, this article explores both micro- and macro-level implications of the use of English as ad hoc institutional standard in the asylum determination interview. At a micro level, this article intends to analyze the implications of lingua franca English usage in asylum interviews: how do differences between varieties of the "same" language interfere with the high discursive demands made on the participants in the asylum interview? To what extent do the participants anticipate and accommodate their interlocutors' linguistic and sociocultural behaviour and expectations? In what ways does lingua franca interaction - and the fact that none of the speakers use English as an L1 - affect the organization and the outcome of the interview? Does this shared non-nativeness also imply equal linguistic opportunities in the interview process? At a macro-structural level, this article 

The Belgian Asylum Interview
(suite)

amines how the ideological implications of lingua franca English usage relate to the interactional dynamics and the underlying power asymmetries of immigration gatekeeping interviews.

To address these questions, this article takes a linguistic ethnography approach, analyzing the everyday practice of asylum officers and their clients as a lens to investigate institutional discourse patterns at a macro-societal level. The analysis presented in this article draws from a set of eight asylum interviews, where asylum officers use English as an interview language, either for direct communication with the asylum English asylum seeker, or, in case of interpreter-mediated interaction, for communication with the interpreter. The for Refugees and Stateless Persons (CGRS) in Brussels, over a period of two year (2011-2012). The CGRS is an independent asylum authority that is authorized to examine and evaluate asylum applications. The asylum interview occupies a central place in the examination at the CGRS. During this interview, asylum seekers have to motivate their application by telling their narrative of escape and by explaining the reasons why they need protection in Belgium. These interviews are not recorded but asylum officers are required to write an interview report. This report is a documentary record of the course of the interview in which "all the asylum seeker's declarations are written down verbatim" (CGRS Interview Charter 2011, 11). In practice however, $\mathrm{t}$ practice however, these on-the-spot transcriptions should rather be considered a exhaustive accounts - instead ofliteral transcriptions - of the information considered relevant by the asylum officer.' At the end of the interview, the asylum office has to check with the applicant if the report contains all the necessary information. It is the task of the asylum authorities to determine whether or not, on the basis of the related narrative, applicants produce a credible account and fulfil the required Convention criteria of refugee status.

This article zooms in on two cases, one case of dyadic applicant-officer interaction and the other involving interpreter-mediated interaction. Microanalysis of the data demonstrates how lingua franca English lacks the resourcefulness needed to properly serve its functions as stipulated in the CGRS's code of conduct and hence of conduct and hence shows how it does not suffice for an adequate understanding and assessment of claims to asylum. At the macro-structural level of analysis, I argue that linguistic inequality arses from the way Englishis used as adhochedum ofentextualization at multiple levels of translation between languages, modalities, and genres. This article concludes with an affirmation of the need for continued interaction between researchers and practitioners in the field to enhance the quality and effectiveness of refugee status determination practices.

\section{RESEARCH SETTING AND METHODOLOGY}

The Belgian asylum procedure is a legal-administrative procedure in which the applicants have to explain their motivation for seeking asylum in Belgium. Like in many other asylum countries, the procedure includes several government authorities, each having specific competences and responsibilities. The Dienst Vreemdelingenzaken or DVZ (Immigration Department) falls under the Ministry of the Interior and is responsible for the registration of the application and carries out some preliminary investigations. The Commissariaat Generaal voor de Vluchtelingen en de Staatlozen or CGRS (Office of the Commissioner General for Refugees and Stateless Persons) is an independent authority that examines the merits of the application and determines the refugee or subsidiary protection status of the applicant The Rad voor Vreemdelingenbetwistingen or ALC (Council for Alien a Law Litigation is a juicing bV or CGRS decisins. Thus, while the registration and the determination of refugee status involve administrative processing of cases, the appeal authority lies with an administrative court of justice.

Article 51/4 of the 1980 Aliens' Act states that the examination of the asylum application is in one of Belgium's official languages, either Dutch or French. The selected language is formalized as the procedural language, that is, the language that is used by the asylum agencies throughout the procedure for both spoken and written communication with the applicant. Applicants who do not speak Dutch or French can be assisted by an interpreter. In this case, the procedural language (Dutch or French) is determined by the Immigration Department. This protocol thus asserts that asylum officers use no other languages than Dutch or French to communicate with the asylum seeker, either directly or through an interpreter This protocol, however, is not being consistently applied across the procedure. It is striking that the function of English as a medium of interaction changes as applicants proceed from administrative to legal stages of investigation. While the protocol is strictly observed in the court of appeal, which works with certified interpreters for mediation between English and the procedural language, it is departed from in the asylum interviews that are part of the preceding administrative phase. In this phase, it has become common practice for asylum officers to conduct the interview in English in cases where either the asylum seeker or the interpreter can express himelf/herself in English. The interpreter then translates from one of the applicant's home languages (not necessarily the preferred language) into English, instead of using Dutch or French as the target language. Accordingly, the use of English in these cases entails a distinction between what is officially recognized as the procedural language - either Dutch or French, the language of the written proceedings - and what is unofficially accepted as the interview language - English, the language used by the asylum officer for oral communication with the asylum seeker or his/her interpreter. Given that in Belgium no audio-recordings are made of the asylum hearing, the use of English in such cases results in an invisible linguistic gap between the language of spoken interaction (English) and the language of the case file (either Dutch or French). In the end, it is the asylum officer who is assumed to fll this gap by providing an off-the- in assyer the asylum seeker's or the interpreter's spoken English account into the procedural
language of the written hearing report. 
That the Belgian asylum agencies have great expectations of their employees linguistic abilities can be derived from the "Interview Charter", issued by the CGRS in 2011. This charter serves as the asylum officer's code of conduct and comprises 12 guidelines on how to interview asylum applicants. One of these guidelines asserts that:

[t]he language used during the interview is adapted to the asylum seeker and to his background The question asked and the information given duing the interview ground. The account the asylun secker's personality, expenince and cultural background (age, gender, account the various aspects of intercultural communication. (CGRS 2011, 13)

Apart from the fact that concepts such as "language adaptation" and "intercultural communication" are not clearly specified, this guideline presumes a transparent relation between language, identity, and socio-cultural origin. Asylum officers are not only expected to understand and take into account a complex set of socia identity variables, they also have to use this understanding to fine tune their speech in anticipation of these variables. Moreover, despite the fact that they usually lack trainingin language and translation, asylum officers are assumed to havesom specific translation competencies.

The methodological approach taken in this study uses linguistic ethnography, incorporating institutional discourse analysis (Rampton 2007; Copland \& Creese 2015) to (2015) to examine the viability of English as an interview language in situated interaction between asylum officers and their clients. The data excerpts are part of a larger corpus of about $30 \mathrm{~h}$ of spoken interaction, collected at the CGRS in Brussels over a period of two years (2011-2012). This has eventually yielded a set of eight audio-recorded asylum interviews, which took about $4 \mathrm{~h}$ each (Table 1 ). In all cases, English is used as an interview language, either for direct communication with the asylum seeker (cases 3-4-5-6), or, in case of interpreter-mediated interaction, for asylum communication with the interpreter (cases 1-2-7-8). For each of Diven access to thecase fles and the intepreters' notes.

Data were collected by observation, note-taking, audio-recording, and transcription of the interaction between asylum seekers, officers, and interpreters, and wer then analyzed at a micro level and related to macro-ideological concerns. This combination of ethnographic and discourse-analytical methods enabled me to explore and demonstrate the potential effects of the participants' sociolinguistic behaviou on the construction of social identities in globalized gatekeeping encounters.
Table 1: Overview corpus 2011-2012

\begin{tabular}{ccccc} 
& Year & Nationality & Mediated & Direct \\
\hline 1 & 2011 & Eritrea & Amharic English & \\
2 & 2011 & Eritrea & Amharic English & \\
3 & 2011 & Nigeria & & Nigerian English \\
4 & 2012 & Gambia & & Gambian English \\
5 & 2012 & Gambia & & Gambian English \\
6 & 2012 & Gambia & & Gambian English \\
7 & 2012 & Somalia & Somali-English & \\
8 & 2012 & Eritrea & Amharic English & \\
\hline
\end{tabular}

The following section presents data extracts from two different asylum interviews: in the first case, English is used as a lingua franca in the dyadic interaction between the asylum seeker and the asylum officer. The second case is an example of interpreter-mediated interaction where English is used for communication between the asylum officer and the interpreter.

\section{DATA EXAMPLE 1: "THUGS" “TALKS"}

The first excerpt is taken from the asylum interview of a Nigerian asylum seeker (AS), conducted by a Flemish asylum officer (AO) working for the CGRS. It comes from the second half of the interview, where the AS is asked to explain his reasons for leaving Nigeria. After having expounded on his political affiliations, the AS provides specific information concerning his personal involvement in the party rivalry between the right wing People's Democratic Party (PDP) and the liberal Action Congress (AC). Specifically he elucidates the circumstances that led to the impeachment of a PDP speaker of the House of Assembly Throughout the interview, ing AO Despite the AO. Despite the immediacy of the spoken interaction, the entextualization of the
account nevertheless involves translation from English (interview language) into account nevertheless involves translation from English (interview language) into Dutch (procedural language) in the AO's written record.

Excerpt $1^{2}$

(1) AO: ok (3.5) so what happened then?

(2) AS: I let down- to- after the incident we came out and we saw that there were lot of thugs outside (.)

(3) AO: talks= people were talking? (4) AS: (thugs= political thugs

(5) $\mathrm{AO}$ : uhum
(2) Transcription conventions

(.) brief pause

(3.5) longer pauses are

\section{no perceptible}

pause between the
speaker's turns

a hyphen after

a word indicates
a cut-off or self-

interruption (e.g.
false starts or when

a part of the
missing)

overlapping speech

CAPITALS increased pitch

AAAAAA Amharic turns

between [] phonetic 

The Belgian Asylum Intervie
(6) AS: you know what political thugs is? (1.5)

(7) AO: ja (3.5)

(8) AS: like (.) as I said cultist (pronounced ['gnlttz]) those are people who politicians send to- to kill people or destroy

(9) AO: oh no I don't $=(\mathrm{xx}$

(10) AS: $\quad$ =yeah fighting $=$

(11) AO: =there were many political

(12) AS: =thugs along the street they were / shooting

(13) AO: $\quad$ (wha -okay then- what is it then?

(14) AS: hen?- They were shooting guns so everybody have to run

(14) AS: hen?- They were shooting guns so everybody have to
(15) AO: but political talks I don't understand them / like this

(15) AO: but political talks I don't understand them / like this
(16) AS:

(16) AS:

(18) AS: political- I can be a political thug(s) like I would be walking (.) with politicians they send me maybe $=$

(19) AO: =is like the "Black Hawks"?

(20) AS: yeah is like a cultist (pronounced ['gNlttz]) yeah so the- the "Black Axe" they send- maybe they want to (.) kill an opponent they send you to go and do the job $($. send- $n$ ay ou for it () or maybe if election is gong on they send people to dob (.) they paidyou for it() or the election steal ballot boxes $(7.0)$

(21) AO: and they were outside?

(22) AS: they were outside so=
(23) AO: =how did you recognize them?

(24) AS: yeah I'm- I'm- I'm- I'm- in "Action Congress" so I know that these people are from the PDP because it was when the incident happened (.) the speaker went out of the house and before we know these people came they started- shooted gun before we know they cau=

(25) $\mathrm{AO}$ : =the speaker went out of the house $=$

(26) AS: =house=

(27) $\mathrm{AO}:=$ and then? They came in?

(28) AS: the p-the- the precincts (pronounced [prekzents]) of the house of assembly not inside (.) the precinct (pronounced [prekzent]) (.) they were outside the assembly's arena so they started shooting gun people were running away (..) before the police came in to put things in order

(29) AO: they c-I don't- this happened outside of the $=$

(30) AS: =the house of assembly (.)

(31) AO: and who was- so the- the political talks how do you write it cause I don't really know how you write "talks" then (.)

(32) AS: I spell it=

(33) AO: =THUGS or- probably- eh (...)

(34) AS: ((writes down the word))

(35) AO: thugs ja

(36) AS: yeah
(37) AO: ja ok (5.0) okay so the political th- thugs- the thugs who were they attacking?

My analysis concentrates on the complex interactional and metalinguistic dynamics of sense making emanating from the AS's use of the term "thugs", a term that displays considerable variation in pronunciation and socio-political meaning. International intelligibility research has shown that some of the features of pronunciation causing the most intelligibility problems are consonant substitutions and vowellength distinctions (Jenkins 2000-Deterding 2012). Loss of intelligibity in the "thus" "thugs" exanple sonant replacement, reduction in vowel quatity and terninal devoicing (Table 2). Moreover, what may further compromise intelligibility is the fact that the word "thugs" is homophonic with "talks" pronounced [toks] in Nigerian English (Bobda 2007, 296-7), which is also very similar to the Flemish pronunciation of "talks" as [tbks] (no word-initial aspiration of [t], localization and shortening of RP /: / for $[b])$. This probably also explains why the AS's realization of RP word-initial dental $/ \theta /$ as $[t]$, reduces intelligibility here, and does not appear, therefore, to comply with Jenkins' exclusion of the dental fricative pair from the lingua franca core $(2000,137)$. Similarly, word-final devoicing of / $\mathrm{gz} /$ seems to exceed the allophonic level (that is, perceived as contrastive/ks/), which in combination with the shorteve shorteningortheprecedinger, these homophones are easily interchangeable in the given context (political thugs/talks),
which probably explains why it takes the interlocutors several turns to detect the which probably exp

Table 2: Nigerian English pronunciation of the word "thugs"

\begin{tabular}{ll}
\hline thugs & \\
\hline RP & {$[\theta \wedge \mathrm{gz}]$} \\
\hline Word-initial dental $/ \theta /$ as $/ \mathrm{t} /$ & {$[\mathrm{t} g \mathrm{gz}]$} \\
Localization of $/ \wedge /$ vowel & {$[\mathrm{t} g \mathrm{gz}]$} \\
Final devoicing of $/ \mathrm{gz} /$ & {$[\mathrm{t} k \mathrm{~s}]$} \\
Nigerian English output & {$[\mathrm{t} k \mathrm{ss}]$} \\
\hline
\end{tabular}

In addition to this phonological explanation, it is also useful to consider the semantic field covered by the English term "thug" as well as its word frequency. The word "thug", apart from its general meaning as "violent person" or "criminal", has a more specific meaning in the Nigerian context, where it refers to local youths who belong to university cult groups that help politicians to silence their adversaries (armed robbery, bribery, and assassination) (Igbafe \& Offiong 2007). The AS obviously refers to this vexed issue of cultism in the Nigerian university system, obviously refers to this vexed issue of cultism in the Nigerian university system, 
verify the AO's familiarity with the political cult system in Nigeria before proceeding with his account. Despite the AO's initial affirmation (turn 7), it is not until turn 12, where the AS refers to the political thugs as active agents (they were shooting), that the $\mathrm{AO}$ comes to realize that they are not on the same wavelength. What follows is a somewhat uneasy conversation (turns 13-18) where the AO interrupts the AS right in the middle of his explanation, impelling him to resume his account, this time adopting a less abstract, first-person perspective. The AO shows that she is now following along as she links up the concept of "political thugs" with the "Black Axe", following alngack Axe", a term the AS had introduced earlier on in the interview - but which the AO then heard as "Black Hawn" - to refer to on of the most However, while the term thugs" is now sufficiently clear for the AO to go ahead with the interview, it requires further specification as soon as the AO proceeds to the process of entering this information in the written record. The fact that the AO urges the AS to spell "thug", indicates that she does not recognize the word from its spoken form. Nevertheless, also after the AS has spelt the word for the AO, the AO apparently still chooses not to translate the word but to preserve the English term "thugs" in her report, without adding any clarification (Excerpt 2). This could be either because she is unable to translate the word (possibly because she is not familiar with it), or because she prefers to stick to the original English word used by the AS to avoid specific meaning getting lost in the translation. In terms of word transparcy relatively low word frequencin Bitsh Engish, especially when compared with the more transparent and more commonly used words "gangster" and "criminal". Interestingly in either case, the AO passes it on to the future readers of the report (decision-makers, appeal judges, lawyers) to solve.

Excerpt 2

Na incident kwamen we naar buiten. er waren veel politieke "thugs", die werken met de politiekers.. Hoe herkend? Ik ben AC, ik weet dat ze van de PDP zijn. De speaker ging naar buiten en wij, AC leden, werden aangevallen door de thugs.

\section{Excerpt $2 \cdot$ my translation}

After the incident we came out, there were many political "thugs", who work with the politicians .... How recognized? I am AC, I know that they belong to the PDP. The speaker went outside and we, $\mathrm{AC}$ members, were attacked by the thugs.

Unlike the "thugs/talks" misinterpretation, however, the "axe/hawks" homophony is not detected during the interview. As a result, the name of the campus cult "Black Axe" "ets errous" in the written record "Black A " lishing the facts, may backfire at a later stage in the procedure.

\section{Excerpt 3}

Van wie kwamen die [de sms'en] dan? Van cultus groep, van black hawks. Hoe weet je dat? ze vermelden black hawks in de SMS-en.

Excerpt 3: my translation

Whom did these [text messages] come from then? From cultist group, from black hawks. How do you know? They mention black hawks in the text messages.

\section{DATA EXAMPLE 2: "HAEMORRHOID(S)"/"HAEMORRHAGE"}

The second example is taken from an interpreted asylum interview between an Amharic-speaking AS from Eritrea and a Flemish CGRS officer (AO), mediated by an Ethiopian Amharic-English interpreter (INT). English, in other words, serves as a spoken target in the triadic interaction where it is used as a lingua franca for direct communication between the INT and the AO. Also in this case, the interpreting process is completed by an additional phase of translation from spoken English to written Dutch. Excerpt 4 is taken from the main part of the interview where to AS is a the AS is asked toxplan the probs already declared in her pevious interview for the Immigration Department that the problems she had in her home country were caused by her membership of the Pentecostal church. At this point in the interview, the AO wants to find out since when and why the AS decided to convert to this religion.

\section{Excerpt 4}

(1) AO: Why did you decide to convert to this religion?

(2) INT: AAAAA (...)

(3) AS: AAAAAA (...)

(4) INT: because of $=$

(5) $\mathrm{AS}=\mathrm{AA}=$

(6) INT: =because of the (.) ['xi:mərert] (.) I was suffering

(7) AO: the what?

(8) INT: ['xi:mərert] ['xi:mərert] [ana'xi:mərert] ['xi:mərert]

(9) INT addressing the researcher (visual ratification): ['xi:morert] don't you know? ehm

(10) Researcher addressing AO (almost inaudible): ['hem.ər.Id3] it is "heavy bleeding"

(11) AO: right ok

(12) INT: thank you ((laughs))

(13) AO: thank you eh (2.0) uhm (2.0) uhm (2.0)

(14) INT: ['xi:morert $]=$ becau $=$

(15) AO: =yeah

(16) INT: $=\mathrm{a}-\mathrm{a}=$ 

The Belgian Asylum Interview
(17) AO: =because that's

(18) INT: =the/'xi:moreit//yeah (.) I had bleeding- continuous bleeding (..) and (..) after I was converted (2.0) let me check (3.0)

My analysis of this excerpt concentrates on the INT's use of the term "haemorrhoid(s)" and the confusion it causes amongst the participants as to pronunciation, semantic meaning, and pragmatic relevance. The AS explains that it was due to her illness - her suffering from anal haemorrhoids - that she converted to the to herillo the Pentecostal church. The AO apparently cannot follow and asks for clarification of ['xi:morert] in line 7. The INT then repeats the term several times and adds "anal" (in itself a pleonasm) to make the meaning of this term explicit. As the AO still doe not understand, the INT makes eye contact with me (the researcher) for confirmation (that this is the correct term to use) and assistance (to help him explain the term for the AO). At this point, however, I unintentionally add to the confusion as I understand the term as "haemorrhage" instead, thereby suggesting the wrong translation "bleeding” ("bloeding") instead of "haemorrhoids" ("aambeien"). The INT nevertheless accommodates to my interpretation of the term as he now pronounces the word-final affricate $/ \mathrm{t} /$ and focuses on the aspect of "continuous bleeding" (turn 18).

The fact that neither the AO nor the researcher recognize the phrase "anal haemorrhoid(s)" from its spoken form can be related to the INT"s Amharic English pronunciation of the phrase. One such feature is the pronunciation of fricatives as ejectives: whereas in English, fricatives are produced with pulmonic airstream Amharic typically has the glottalic mechanism to produce stops and fricatives (Sharma 2013). By transferring this mechanism to English, Amharic English speakers, like the INT in Excerpt 4, tend to produce the glottal fricative $/ \mathrm{h} /$ as velar ejective fricative $[x]$. The INT's pronunciation of "ae" as [i:] in the first syllable of "haemorrhoid(s)" may point to an analogy with other words of Greek-Latin origin such as encyclopaedia and archaeology. Furthermore, as in many other African Englishes, RP word-internal schwa has a variety of strong vowels that are pronounced by analogy woth the with "he spelling of the word, such as [] for orthographic "o

While the INT's pronunciation of the first two syllables of the term "haemorrhoid(s)" complies with some of the typical pronunciation patterns of Amharic English, the third syllable displays significant variation in the pronunciation of the diphthong and the word-final cluster $/ \mathrm{dz} /$. We should note here that the INT has already used this term earlier on in the interview, in the passage where the AS explains why she was released from prison (Excerpt 5). It is striking and difficult to explain that while in Excerpt 4, the INT pronounces the third syllable as [ert], this syllable is pronounced [ars] in Excerpt 5 (Table 4).
Table 4: Amharic English pronunciation of the word "haemorrhoid(s)"

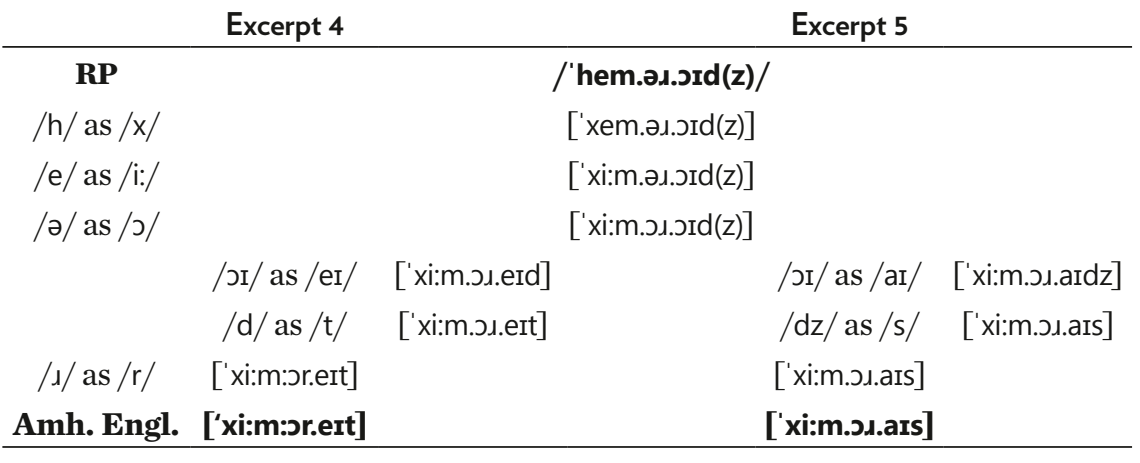

Excerpt 5

INT: They were (.) forced to release me (..) because of (4.0) health problem (4.0) mainly () ['xi-mərars] () ['xi-morars] (30) I had- I got ['xi-mərars] on my a- [ana 'xi:morars] (.) and it was constantly blecting (20) and they (20) released me on condition (30) to and treatment for that $($.

Interestingly, also in this instance, the INT first repeats the term and then adds an important clarification by adding "anal". As with "haemorrhoid(s)", also the word "anal" is not recognized from its spoken form and this can again be related to the INT's Amharic English pronunciation of the word: RP / kee.nər/ is pronounced [ana], involving spelling pronunciation of both the diphthong/er/and word-internal schwa as [a], as well as deletion of the word-final consonant (both features are typical for Amharic English, Sharma 2013, 79). However, we should note that because of its specific pronunciation pattern and the fact that it is pronounced rather quickly in combination with "hemorrhoid(s)" I understood the term " combicters when tras in which the INT already related his health problem to "constant bleeding" earlier in the interview (Excerpt 5) is probably why I suggested "haemorrhage" instead of "haemorrhoids" in Excerpt 4. Moreover, what may have increased confusion between these two cognates (from Greek "haima, haimatos", meaning "blood") is the fact that the third syllable is pronounced [er] rather than /I/, as suggested by the spelling of the word "haemorrhoid". This is probably what made me suggest the word "haemorrhage" instead, assuming that the INT's substitution of RP/I/ by [eI] (haemorrhage) may indicate an analogy with more common words with the same ending like "engage" or "page".

Moreover the meaning of the term cannot easilybe inferred from its context because important details - the relation between the AS's reported disease and her conversion - remain largely implicit. Some essential socio-cultural background on 
The Belgian Asylum Interview the role of Pentecostalism in Eritrean society is needed to understand the prag-
(suite) matic relevance of the AS's answer: (a) that Pentecostals form a minority Christian movement in Eritrea that has become the focus of religious persecution around the turn of the century, at the time when the Eritrean government ordered the closure of several religious institutions (Kagan 2010); and (b) that Pentecostals believe in spiritual intervention in illness through prayer and ritualistic practices (UNHCh 2009). All in all, the INT's inconsistent pronunciation of this word in combination with its semantic meaningand the pragmatic relevance of its use in the withich makes it difficult for the interlocutors to derive its meaning from its pronunciation, which results in multiple interpretations and possibilities for misunderstanding

\section{CONCLUSION: INSTITUTIONAL ENGLISH IDEOLOGY}

The data analyzed in this article demonstrate how difficult it is for asylum applicants, officers and interpreters alike to meet the very high linguistic expectation set by the asylum institution. Rather than offering just another illustration of mismatches and communicativebreakdowns in asylum interaction these data examples lay bare some easily overlooked intricacies of English usage in sylum encounters. First, in view oft First, in view of the institutionally expected degrees of accuracy and factual detail, asylum interviews require an advanced level of English, which involves familiarity with specific terminology and less commonly used words such as "thugs" or "haemorrhoid(s)". Secondly, given the specificity of each individual asylum application - often involving complex cultural and socio-political conditions that need to be specified - the interview participants need to be abreast of specific connotations and local collocations of English terms as they are being used across socio-cultural boundaries, such as the precise socio-political meaning of the word "thug" in the context of the Nigerian conflict. Thirdly, given that the interview participants have their own variants of English pronunciation that may be very different from thei interlocutors' spech, particular words and phrases - such as “thugs" or "anal haem" orrhoid" this amalgan of factors complicates the issue of fulfilling institutional demands of accuracy and precision. Albl-Mikasa (2013) made similar observations in a conference interpreting setting where lingua franca English users were dissatisfied with their limited capability of communicating their views with the desired "subtlety and delicacy in the nuances of their expressions" (109). Such inadequacies could prove particularly problematic in the asylum procedure, where every misunderstanding or inaccuracy may rebound on the individual asylum seeker in the further course of the procedure.

While on the basis of the participants' shared non-nativeness, English may be how it nevertheless exercises a gatekeeping function in representing and assessing asylum accounts. Despite the interlocutors' use of pragmatic strategies to negotiate difference and have their voice heard in the interview interaction, this capacity for mutual and intersubjective meaning-making decreases as the asylum seeker's voice is eventually entextualized - de- and recontextualized (Silverstein \& Urban 1996) - in the institutional participants' constitutive processes of translation and recordkeeping. Institutional inequality of voice - used here in the Hymesian sense as "the capacity to make yourself understood on your own terms" (Blommaert 2006, 166) - arises indirectly from the privileged status granted to the variety of the host institution to act as a "standard" medium of entextulization at multiple levels of institution to act as a stong translationbetween languges (Enliting), and genres (interview and report). The way tion is attributed a key role in the entextualization of asylum accounts turns it into an enfranchising and empowering variety that is used to monitor the discourses of other participants (asylum seekers, interpreters) in the asylum process.

Interestingly, the immigrant participants were able to express themselves more accurately and fluently than the institutional representatives, given the status of English as the medium for instruction in their respective home countries. In both data cases, it is the African English speaker who accommodates to the linguistic needs of the Flemish bureaucrat. But still, while linguistic relations may be inverted, power relations arent. The participants with the leastlinguistic resurce in the nterview process have the institutional power to act as arbiters of what is/is not institutionally relevant for the textual file. ${ }^{3}$ If several actors - asylum officers, interpreters, appeal judges, and so on - are involved in the entextualization of the account, certain conditions of textual reproduction may need to be anticipated in the interaction itself. Differential control over the factors that determine what gets entextualized and how, may cause every misunderstanding or inaccuracy in the interaction to rebound on the individual asylum seeker in the further course of the procedure. Therefore, in order to avoid misunderstandings, it is of crucial importance that asylum seekers are given the opportunity to verify the accuracy of the written report, if necessary with the assistance of an interpreter, before signing it for approval ${ }^{4}$ In addition,

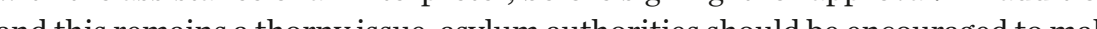
audio and/o video recordings of the asylum intervew as at

To conclude, the data have shown how homogenizing and standard-oriented notions of English may lead to facile and reductive assessments of asylum accounts in the Belgian asylum procedure. The question is whether Belgium is the only EU country that circumvents its language legislation. Exploratory research on the use of English as an interview language in EU asylum countries indicates that also in several other EU member states where English has no official status (such as the Netherlands and the Scandinavian countries), English is increasingly used as a contact language in (semi-)bureaucratic settings for communication with foreign-language speakers. in view of the rapid increase of English as a lingu franca in the $\mathrm{EU}$, further investiInview of the rapidiner tional encounters is needed, particularly in those settings where complex multidiscursive and language
(3) For more examples, I refer to
Maryns 2005; 2006; 2012. (4) UNHCR has reported that in some Member States still inng Belgium, there are
stil invewers who ask the applicants to sign their report for opportunity to verify the report for accuracy and correctness (5) Today, this is consistently condtitions (on request, interers)
with unaccompanied minors with
in the Netherlands and the UK
(UNH 
ideologically anchored processes may affect the representation of discourse in ways that are often beyond the control of those to whom it matters most.

This paper is a slightly modified version of an article that was published in Applied Linguistics (2015, 1-23), entitled
'The Use of English as ad hoc Institutional Standard in the Belgian Asylum Interview'

\section{WORKS CITED}

- Alb-Mikasa, Michaela, 'Express-ability in ELF communication', Journal of English as a Lingua Franca 2(1), 2015, - Angermeyer, Philipp Sebastian, 'Multilingual speakers and language choice in the legal sphere', Applied
Linguistics Review 4(1), 2013, 105-126. - Bhatt, Rakesh Mohan, 'Experts, dialects, and discourse' International Journal of Applied Linguistics 12(1), 2002 74-109.

- Blommaert, Jan, 'Commentary: A sociolinquistics of globalization,' Journal of Sociolinquistics 7, 2003, 607-623.

- -.-, Discourse: A Critical Introduction, Cambridge University Press, 2005.

-.-., 'How legitimate is my voice? A rejoinder', Target 18(1), 2006, $163-176$.

--.-, The Sociolinguistics of Globalization, Cambridge University Press, 2010.

- -..., James Collins \& Stef Slembrouck, 'Spaces of multilingualism', Language and Communication 25, 2005,

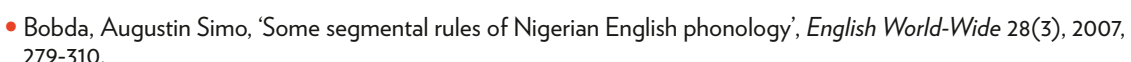
279-310.

- Canagarajah, Suresh, Translingual Practice: Global Englishes and Cosmopolitan Relations, Routledge, 2013.

- Copland, Fiona \& Angela Creese, Linguistic Ethnography: Collecting, Analysing and Presenting Data. Sage, 2015. - Coupland, Nicholas, Howard Giles \& John M. Wiemann (eds), "Miscommunication" and Problematic Tall, Sage
Publications. 1991.

- Eades, Diana, Courtroom Talk and Neocolonial Control, Mouton de Gruyter, 2008

- Ellis, Rod, The Study of Second Language Acquisition, Oxford University Press, 1994. - Gal, Susan, 'A linguistic anthropologist looks at English as a lingua franca', Journal of English as a Lingua Franca
$2(1), 2013,177-183$. - General Commissioner's Office's for Refugees and Stateless Persons, Interview Charter, CGRS Belgium, 2011. - Guido, Maria Grazia, English as a Lingua Franca in Cross-cultural Immigration Domains, Peter Lang, 2008. - Gumperz, John J., Discourse Strategies, Cambridge University Press, 1982.

- Haviland, John, 'Ideologies of language: Reflections on language and US law', American Anthropologist 105,
2003, 764-174.
- Hülmbauer, Cornelia, “'You moved, aren't'? - The relationship between lexicogrammatical correctness and communicative effectiveness in English as a Igbafe, Afeaye Anthony O.J. Offiong, 'Political assassinations in Nigeria: An exploratory study', African Journal of Political Science and Internationa

- Jenkins, Jennifer, The Phonology of English as an International Language, Oxford University Press, 2000.

- Kachru, Braj B., 'Asia's Englishes and World Englishes', English Today 16(1), 2000, 17-22.

- Kagan, Michael, "Refugee credibility assessment and the "Religious Imposter" problem: A case study of Eritrean Pentecostal claims in Egypt', Vanderbilt
Journal of Transnational Law 4(5), 2010, 1179-1233.

- Maryns, Katrijn, 'Monolingual language ideologies and code choice in the Belgian asylum procedure', Language and Communication 25(3), 2005, 299-

-.-- The Asylum Speaker: Language in the Belgian Asylum Procedure, Routledge, 2006

-.-.- 'Multilingualism in legal settings', in Marilyn Martin-Jones, Adrian Blackledge \& Angela Creese (ed.): Routledge Handbook of Multilingualism,
Routtedge, 2012, 297-513.

-.-., 'Procedures without borders: The language-ideological anchorage of legal-administrative procedures in translocal institutional settings', Language in
Society $42(1), 2013,70-92$

- Mauranen, Anna, Exploring ELF: Academic English Shaped by Non-Native Speakers, Cambridge University Press, 2012.

- Milroy, James, 'Language ideologies and the consequences of standardization', Journal of Sociolinguistics 5, 2001, 530-55.

---- \& Lesley Milroy, Authority in Language: Investigating Language Prescription and Standardisation, Routledge, 1999.

- O'Regan, John P., 'English as a lingua franca: An immanent critique', Applied Linguistics 35(5), 2014, 533-552.

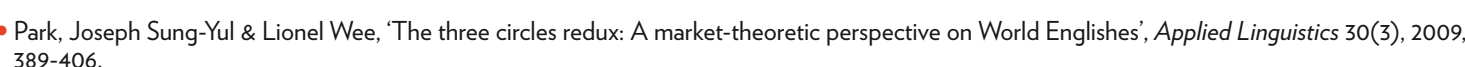

- Pavlenko, Aneta \& Adrian Blackledge, 'New theoretical approaches to the study of negotiation of identities in multilingual contexts', in Ibid. (ed.),
Negotiation of Identities in Multilingual Contexts. Multilingral Matters, $2004,1-33$.

- Pennycook, Alastair, The Cultural Politics of English as an International Language, Longman, 1994.

-.-., 'Multilithic English(es) and language ideologies', Language in Society 37, 2008, 435-444.

- Rampton, Ben, Language in Late Modernity, Cambridge University Press, 2006

-.-., 'Neo-Hymesian linguistic ethnography in the United Kingdom', Journal of Sociolinguistics 11(5), 2007, 584-607.

- Roberts, Celia, 'Translating global experience into global models of competency: Linguistic inequalities in the job interview', Diversities 14(2), 2012,

- Saraceni, Mario, 'English as a lingua franca: Between form and function', English Today 24(20), 2008, 2-26.

- Seidhofer, Barbara, Anglophone-centric attitudes and the globalization of English', Journal of English as a Lingua Franca 1(2), 2012, 393-407. - Sharma, Gopal, 'English in Ethiopia', Science, Technology and Arts Research Journal 2(1), 2013, 74-85.

- Silverstein, Michael, 'The indeterminacy of contextualization: When is enough enough?', in Peter Auer \& Aldo Di Luzio (ed.), The Contextualization of
Language. John Benjamins, 1992. 55-76.

-..., 'Monoglot "standard" in America: Standardization and metaphors of linguistic hegemony', in Donald Brenneis \& Ronald K. S. Macaulay (ed.), The - --- \& Greg Urban (ed.). Natural Histories of Discourse, University of Chicago Press 1996.

- UN High Commissioner for Refugees. UNHCR Eligibility Guidelines for Assessing the International Protection Needs of Asylum Seekers from Eritrea,
April 2009. Available at http://uww.refworld.org/docid/49deo6122.hthm (accessed May 2016).

- UN High Commissioner for Refugees, Improving Asylum Procedures. Comparative Analysis and Recommendations for Law and Practice, UNHCR, 2010 - UN High Commissioner for Refuges. Handbook on Procedures and Criteria for Determining Refugee Status under the 1951 Convention and the 1967
Protocol Relating to the Status of Refuguees [1979], UNHCR, 2011. - Wiley, Terrence G. \& Marguerite Lukes, 'English-only and Standard English ideologies in the U.S.', Tesol Quarterly 30(3), 1996, 511-535. 